\title{
Wasting as an independent predictor of mortality in patients with cystic fibrosis
}

\author{
R Sharma, V G Florea, A P Bolger, W Doehner, N D Florea, A J S Coats, M E Hodson, \\ $S$ D Anker, M Y Henein
}

Department of Cystic Fibrosis, Royal Brompton Hospital and Harefield NHS

Trust, London, UK M E Hodson

Department of Clinical Cardiology, National Heart \& Lung Institute, Imperial College School of Medicine, London SW3 6LY, UK

$\mathrm{R}$ Sharma

V G Florea A P Bolger

W Doehner

N D Florea

A J S Coats

S D Anker

M Y Henein

Franz-Volhard-Klinik (Charité, Campus Berlin-Buch) at Max-Delbrück-Centrum for Molecular Medicine, Berlin, Germany

W Doehner

$S$ D Anker

Correspondence to:

Dr S D Anker

s.anker@ic.ac.uk

Received 27 October 2000 Returned to authors 24 January 2001

Revised version received

19 March 2001

Accepted for publication

23 April 2001

Table 1 Baseline clinical characteristics of 584 consecutive patients with cystic fibrosis (CF)

\begin{tabular}{llll}
\hline & & \multicolumn{2}{l}{ Comparison by survival status } \\
\cline { 3 - 4 } & $\begin{array}{l}\text { All CF patients } \\
(n=584)\end{array}$ & Died $(n=137)$ & Alive $(n=447)$ \\
\hline Age (years) & $21(7)$ & $22(7)$ & $21(7)$ \\
Sex $($ MF $)$ & $323 / 261$ & $73 / 64$ & $250 / 197$ \\
FEV & $(1)$ & $1.1(0.5)$ & $2.1(1.0) \dagger$ \\
$\%$ predicted FEV & $1.8(1.0)$ & $32(15)$ & $58(25) \dagger$ \\
$\%$ ideal weight & $52(26)$ & $82(15)$ & $95(18) \dagger$ \\
$\mathrm{PaO}_{2}(\mathrm{kPa})$ & $92(18)$ & $8.7(1.5)$ & $10.2(1.9) \dagger$ \\
$\mathrm{PaCO}_{2}(\mathrm{kPa})$ & $9.8(1.9)$ & $5.3(1.1)$ & $4.9(0.8)^{\star}$ \\
\hline
\end{tabular}

Data are presented as mean (SD) or numbers of patients.

$\mathrm{FEV}_{1}$ = forced expiratory volume in one second; $\%$ ideal weight $=$ weight as percentage of the predicted ideal weight; $\mathrm{PaO}_{2}=$ arterial oxygen tension; $\mathrm{PaCO}_{2}=$ arterial carbon dioxide tension

${ }^{\star} \mathrm{p}<0.01,+\mathrm{p}<0.0001$ for unpaired $t$ test of mean of corresponding groups. curve $0.83 ; 95 \%$ CI 0.78 to 0.87 ) and $\%$ ideal weight (area under curve $0.74 ; 95 \%$ CI 0.68 to 0.79 ) were accurate predictors of survival at 5 years follow up (receiveroperating characteristic analysis).

Conclusions-Body wasting is a significant predictor of survival in patients with CF independent of lung function, arterial blood oxygen and carbon dioxide tensions. (Thorax 2001;56:746-750)

Keywords: cystic fibrosis; wasting; survival

Cystic fibrosis (CF) is the most common life threatening autosomal recessive disorder in the white population, occurring at a frequency of approximately $1: 2000$ to $1: 2500$ live births. Advances in medical treatment have resulted in an improvement in prognosis and symptoms with increasing numbers of patients surviving into adult life. However, as the disease progresses, patients develop disabling lung disease with the main cause of death in adults being respiratory failure. ${ }^{2}$ For patients with advanced CF, lung or heart-lung transplantation represents an important treatment for improving survival and quality of life. ${ }^{3}$ In view of the shortage of donor organs and to assess the suitability of patients for transplantation, reliable prognostic indicators that can accurately define groups of patients at high risk are needed.

Wasting has long been recognised as a marker of impaired survival in $\mathrm{CF}^{4}$ but it has not been previously shown to be independent of established prognostic indicators. Kerem et $a \bar{l}$ showed that body wasting was predictive of impaired survival but this was not independent of lung function or arterial blood gas tensions. It has been demonstrated that cachexia is a strong and independent risk factor for mortality in patients with chronic heart failure, ${ }^{6}$ as well as other chronic diseases. ${ }^{78}$ We have examined whether body wasting is an independent prognostic marker in CF.

\section{Methods}

STUDY POPULATION AND FOLLOW UP

Between 1985 and 1996, 584 patients (261 female) with $\mathrm{CF}$, of mean age 21 (7) years (range 7-45), who attended the Royal Brompton Hospital were studied. The diagnosis of CF 
Table 2 Cox proportional hazards analysis of survival in 584 patients with cystic fibrosis: univariate analysis

\begin{tabular}{llll}
\hline Parameter & $\chi^{2}$ value & $p$ value & $R R(95 \% \mathrm{CI})$ \\
\hline FEV $_{1}$ & 137.0 & $<0.0001$ & $0.999(0.998$ to 0.999$)$ \\
$\%$ predicted $\mathrm{FEV}_{1}$ & 143.3 & $<0.0001$ & $0.945(0.934$ to 0.956$)$ \\
$\%$ ideal weight & 62.0 & $<0.0001$ & $0.955(0.944$ to 0.967$)$ \\
$\mathrm{PaO}_{2}$ & 21.7 & $<0.0001$ & $0.730(0.637$ to 0.838$)$ \\
$\mathrm{PaCO}_{2}$ & 4.0 & 0.04 & $1.280(1.009$ to 1.622$)$ \\
Age (years) & 0.7 & 0.406 & $1.010(0.986$ to 1.034$)$ \\
Female sex & 1.2 & 0.280 & $1.203(0.860$ to 1.684$)$ \\
\hline
\end{tabular}

$\mathrm{FEV}_{1}=$ forced expiratory volume in one second $\mathrm{PaO}_{2}=$ arterial oxygen tension $; \mathrm{PaCO}_{2}=$ arterial carbon dioxide tension; $\%$ ideal weight $=$ weight as percentage of the predicted ideal weight.

Table 3 Cox proportional hazards analysis of survival in 584 patients with cystic fibrosis: multivariate analysis

\begin{tabular}{lcll}
\hline Parameter & $\chi^{2}$ value & $p$ value & $R R(95 \% C I)$ \\
\hline \% ideal weight & 5.9 & 0.015 & $0.984(0.971$ to 0.997$)$ \\
\% predicted FEV & 63.4 & $<0.0001$ & $0.951(0.940$ to 0.963$)$ \\
\% ideal weight & 56.5 & $<0.0001$ & $0.955(0.944$ to 0.967$)$ \\
Age & 0.5 & 0.476 & $0.990(0.963$ to 1.018$)$ \\
\% ideal weight & 53.8 & $<0.0001$ & $0.956(0.944$ to 0.967$)$ \\
Female sex & 0.3 & 0.611 & $1.091(0.779$ to 1.529$)$ \\
\% ideal weight & 8.4 & 0.004 & $0.968(0.947$ to 0.990$)$ \\
\% predicted FEV & 17.4 & $<0.0001$ & $0.953(0.931$ to 0.975$)$ \\
$\mathrm{PaO}_{2}$ & 1.7 & 0.187 & $0.892(0.752$ to 1.057$)$ \\
$\mathrm{PacO}_{2}$ & 5.1 & 0.024 & $0.714(0.533$ to 0.957$)$ \\
$\mathrm{Age}^{\text {Female sex }}$ & 1.0 & 0.328 & $0.982(0.946$ to 1.019$)$ \\
& 0.05 & 0.819 & $0.945(0.581$ to 1.537$)$
\end{tabular}

$\mathrm{FEV}_{1}=$ forced expiratory volume in one second $\mathrm{PaO}_{2}=$ arterial oxygen tension; $\mathrm{PaCO}_{2}=$ arterial carbon dioxide tension; $\%$ ideal weight $=$ weight as percentage of the predicted ideal weight.
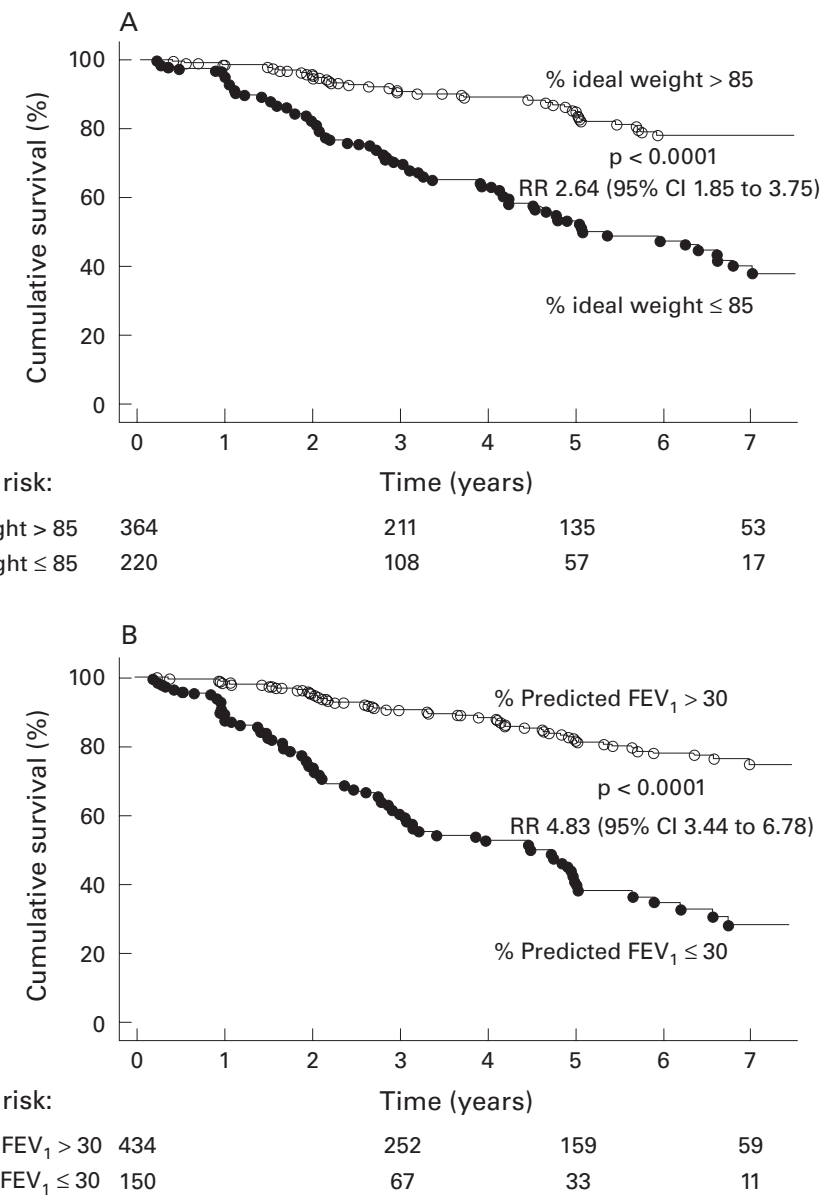

$\%$ Predicted $\mathrm{FEV}_{1}>30434$

$\%$ Predicted $\mathrm{FEV}_{1} \leq 30 \quad 150$

67

33

11

Figure 1 Kaplan-Meier survival plot for 584 patients with cystic fibrosis: patients subgrouped according to (A) percentage ideal weight and (B) percentage predicted forced expiratory volume in one second $(F E V)$. was based on positive sweat tests with typical clinical findings, with or without genotype confirmation. The patients underwent routine testing of pulmonary function during their follow up, with forced expiratory volume in one second $\left(\mathrm{FEV}_{1}\right)$ expressed as a percentage of the normal predicted values for height and sex ( $\%$ predicted $\mathrm{FEV}_{1}$ ), as previously described. ${ }^{9} 10$ Height, weight, arterial blood oxygen and carbon dioxide tensions $\left(\mathrm{PaO}_{2}, \mathrm{PaCO}_{2}\right)$ were also measured. Weight was calculated as a percentage of the ideal body weight for age, height, and sex using the standards of Tanner et $a l^{11}$ for patients aged $\leqslant 19$ years and the Metropolitan height and weight tables ${ }^{12}$ for patients $>19$ years of age.

As all the above investigations were part of the routine assessment of patients with CF attending our hospital, informed consent from the patients studied or ethics committee approval was deemed unnecessary.

\section{STATISTICAL ANALYSIS}

All results are presented as mean (SD) values. Cox proportional hazard analysis was performed using baseline values to assess the association between variables and all-cause mortality. Previous studies have shown that \% predicted $\mathrm{FEV}_{1}$, age, and sex all relate to survival. The interaction between the effects of each of these variables and \% ideal weight in determining survival was therefore evaluated initially in two variable models. Subsequently, these parameters (together with arterial blood gas levels) were included in a six variable model (table 3). Hazard ratio (RR) and 95\% confidence interval (CI) for risk factors as well as significance levels for $\chi^{2}$ (likelihood ratio test) are given, and Kaplan-Meier cumulative survival plots were constructed (StatView 5, Abacus Concepts, Berkeley, USA). The receiveroperating characteristic curves for $\%$ predicted $\mathrm{FEV}_{1}, \%$ ideal weight, and $\mathrm{PaCO}_{2}$ were drawn and the areas under the curves calculated (MedCalc 5.0, MedCalc Inc, Belgium). The cut off level that resulted in the highest product of sensitivity and specificity was considered the optimal level for predicting outcome.

The probability of death within 5 years of patients with CF (according to \% predicted $\mathrm{FEV}_{1}$ and \% ideal weight) was calculated using a logistic regression analysis technique. ${ }^{13}$

\section{Results}

Of the 584 patients who were followed up for a mean of 45 (27) months, 137 (23.5\%) died after 2.4-89.9 months (mean 31.0 (21.0); median 25.0). The mean (SD) follow up period of the 447 survivors was 48.0 (27.1) months (range 1.6-94.7). The cumulative survival of all patients was $96.3 \%$ at 1 year $(95 \%$ CI 94.7 to 97.9 ), $82.8 \%$ at 3 years (95\% CI 79.4 to 86.2$), 71.9 \%$ at 5 years $(95 \%$ CI 67.3 to 76.5 ), and $62.7 \%$ at 7 years (95\% CI 56.9 to 68.5). For all the 584 patients the mean FEV recorded at the start of study was $1.8(1.0) 1$ $\left(52 \quad(26) \%\right.$ predicted $\left.\mathrm{FEV}_{1}\right), \mathrm{PaO}_{2} 9.8$ (1.9) $\mathrm{kPa}, \mathrm{PaCO}_{2} 5.0(0.9) \mathrm{kPa}$, and \% ideal weight 92 (18)\% (table 1). 


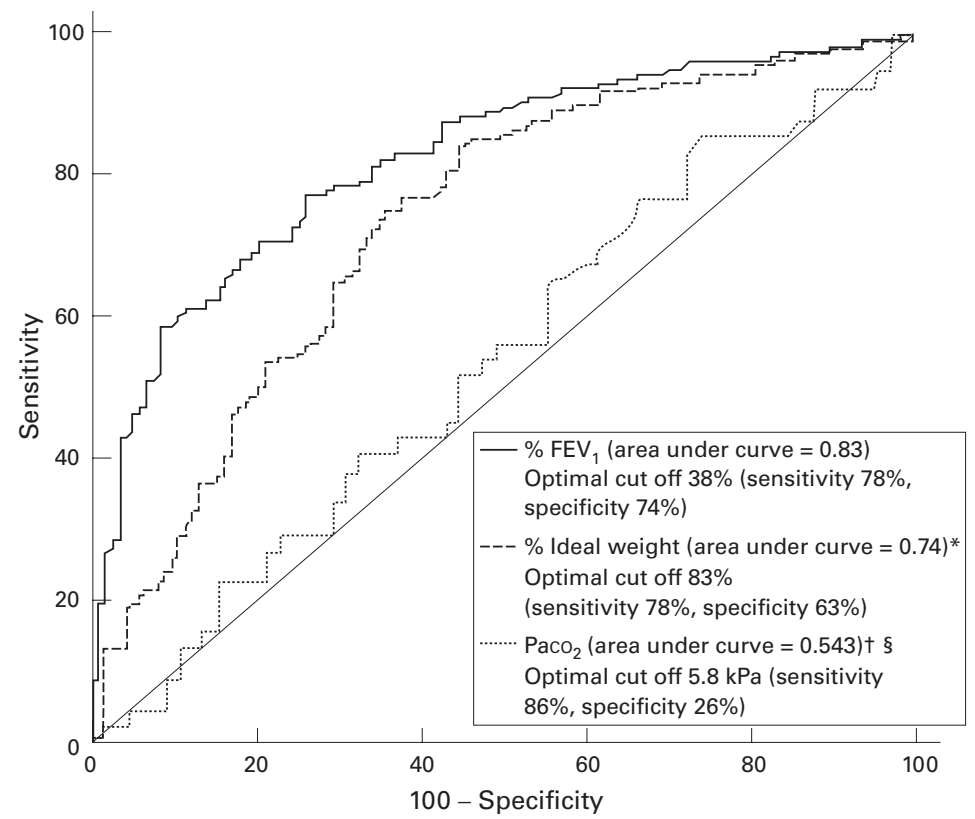

Figure 2 Receiver-operating characteristic curves of 5 year survival for percentage predicted forced expiratory volume in one second (FEV), \% ideal weight, and $\mathrm{PaCO}_{2}$ in patients with cystic fibrosis. ${ }^{\star P e r c e n t a g e}$ ideal weight $v$ percentage predicted $F E V_{1}: p=$ 0.002 ; tpercentage ideal weight $v \mathrm{PaCO}_{2}: p=0.011 ; \mathrm{PaCO}_{2} v$ percentage predicted $\mathrm{FEV} V_{1}$ : $p<0.0001$.

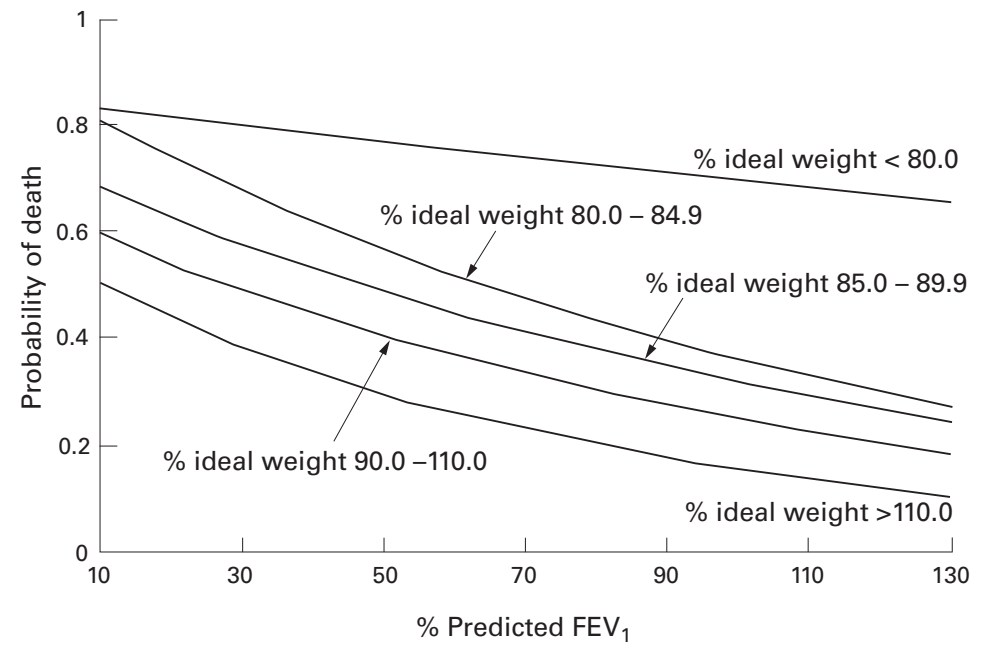

Figure 3 Estimated probability of death within 5 years of patients with cystic fibrosis according to percentage predicted $F E V_{1}$ and percentage ideal weight.

$\mathrm{FEV}_{1}, \%$ predicted $\mathrm{FEV}_{1}, \%$ ideal weight, $\mathrm{PaO}_{2} \quad($ all $\mathrm{p}<0.0001)$ and $\mathrm{PaCO}_{2}(\mathrm{p}=0.04)$ predicted survival (table 2). In multivariate analysis including these measurements, \% predicted $\mathrm{FEV}_{1}(\mathrm{p}<0.0001)$, \% ideal body weight $(\mathrm{p}=0.004)$, and $\mathrm{PaCO}_{2}(\mathrm{p}=0.02)$ were found independently to predict outcome after 5 years (table 3). Age and sex were not predictive of survival in univariate or multivariate analyses.

Kaplan-Meier survival analysis shows that patients with $>85 \%$ ideal body weight had a better prognosis at 5 years (cumulative survival $83.8 \% ; 95 \%$ CI 78.8 to 88.8 ) than those with $\leqslant 85 \%$ ideal weight (survival $53.4 \%$; 95\% CI 45.2 to $61.6 ; \mathrm{p}<0.0001$, fig $1 \mathrm{~A})$. Furthermore, patients with $\mathrm{FEV}_{1}>30 \%$ predicted were found to have a significantly better prognosis than those with $\mathrm{FEV}_{1} \leqslant 30 \%$ predicted (fig 1B).
Receiver-operating characteristic (ROC) curves were plotted for $\%$ predicted $\mathrm{FEV}_{1}, \%$ ideal weight, and $\mathrm{PaCO}_{2}$ (fig 2). Both \% predicted $\mathrm{FEV}_{1}$ (area under the curve 0.827; $95 \%$ CI 0.780 to 0.867 ) and \% ideal weight (area under the curve $0.736 ; 95 \%$ CI 0.684 to 0.785) were found to be highly accurate predictors of 5 year survival, with the former being significantly better than the latter $(p=0.002)$. In contrast, $\mathrm{PaCO}_{2}$ was not shown to be an accurate prognostic indicator (area under the curve $0.543 ; 95 \%$ CI 0.445 to 0.639 ). ROC curves were also drawn for $1,2,3$, and 7 years follow up which resulted in similar results to those above (data not shown). The optimal cut off value for predicting death at 5 years was $38 \%$ for predicted $\mathrm{FEV}_{1}$ and $83 \%$ for ideal weight.

The probability of death within 5 years was estimated according to \% predicted $\mathrm{FEV}_{1}$ and $\%$ ideal weight (fig 3). For any given \% predicted $\mathrm{FEV}_{1}$, the probability of death was found to increase markedly as the \% ideal weight decreased. The probability of death within 2 and 7 years was also calculated, resulting in similar findings (data not shown).

\section{Discussion}

This study has shown that body wasting is an important predictor of impaired survival in CF. It provides prognostic information independently of established risk factors such as lung function ( $\%$ predicted $\left.\mathrm{FEV}_{1}\right)$ and arterial blood gas tensions $\left(\mathrm{PaO}_{2}\right.$ and $\left.\mathrm{PaCO}_{2}\right)$. Although it has long been recognised that wasting is a predictor of survival in $\mathrm{CF}^{4}$ it has not been previously shown to be an independent prognostic indicator.

In a study by Kerem et $a l, 5 \%$ ideal weight was not found to be an independent predictor of survival, in contrast to the present study. One reason for this may be that our data are more recent (patients followed up between 1985 and 1996) than those of Kerem et al (patients followed up between 1977 and 1989). During the last two decades there have been major improvements in the nutrition of patients with $\mathrm{CF}$, with the introduction of high calorie diets and the development of better pancreatic enzymes in the mid 1980 s. ${ }^{14}$ It may be hypothesised that, in the past, if a patient with CF was cachectic this was simply due to poor nutrition, which is why body weight was a relatively weak marker of disease severity in the study by Kerem et al. However, since the advances in nutritional support, the development of weight loss (or failure to thrive in children) is likely to be due to a serious deterioration in the metabolic status of the patient as a result of the disease process itself. As a result, a low $\%$ ideal body weight has become a more powerful and independent predictor of survival in patients with $\mathrm{CF}$ who are managed using present day treatment strategies. It must be borne in mind that, as new therapies for chronic diseases emerge, the prognostic value of certain markers may change, as has been observed in other disease states. ${ }^{15}$

In the present study, age and sex were not significant predictors of mortality in CF. 
Although there have been some previous studies in which these parameters were found to be of prognostic value, there have also been several studies in which this was not the case. ${ }^{416-18}$ In particular, in one of the largest epidemiological studies to date in CF which investigated over 21000 patients, sex was noted to be a significant predictor of mortality only in patients below 20 years of age. ${ }^{18}$ Furthermore, in the same study there was a trend within the 1-20 year age group for the relative risk to diminish with increasing age. As the mean age of our study population was 21 years, this may explain why we did not find sex to be a significant prognostic marker for CF.

One of the major problems of research into cachexia is in defining the degree of wasting. The body mass index is routinely used for assessing weight in relation to height in adults, but this method gives only limited information and cannot be applied to children. Instead, calculating the weight as a percentage of the ideal weight (according to height, age and sex) is more appropriate. ${ }^{11} 1219$ Percentage ideal weight measurements are generally considered superior to the $\%$ average weight of the respective populations when performing survival studies, as the former refer to the weight associated with the lowest mortality rate. ${ }^{20}$ The present study has shown that \% ideal weight is a highly accurate prognostic indicator, with the optimal cut off level being $83 \%$ for predicting 5 year survival. This finding is in keeping with a consensus report on nutritional assessment in $\mathrm{CF}^{19}$ which defined nutritional failure as a $\%$ ideal weight of $<85$. The marked difference in survival between patients subdivided according to $85 \%$ ideal weight is shown in fig 1 .

As $\%$ predicted $\mathrm{FEV}_{1}$ and \% ideal weight were the only two risk factors that predicted death independently and accurately in our study, the probability of death within 5 years was estimated using a model based on these two variables (fig 3). Graphs were also constructed based upon the probability of death within 2 and 7 years which yielded similar results (data not shown). In fig 3, patients were divided into subgroups according to $\%$ ideal weight using a classification system modified from Waterlow and Rutishauser. ${ }^{21}$ The range of body size for normal nutritional status is $90-110 \%$ of ideal weight. Patients with $85.0-89.9 \%$ of ideal weight are defined as having early malnutrition, $80.0-84.9 \%$ as mild malnutrition, and $<80 \%$ as moderate to severe malnutrition. ${ }^{19}$ From fig 3, the probability of death within 5 years can be estimated for any patient provided their \% predicted $\mathrm{FEV}_{1}$ and \% ideal weight are known, both of which can be readily assessed in the outpatient clinic. As a patient's nutritional status worsens, the probability of death for any given $\%$ predicted $\mathrm{FEV}_{1}$ increases markedly. The development of cachexia in CF should therefore be considered an ominous clinical sign. Interestingly, patients in our study who were overweight $(>110 \%$ ideal weight) had a better prognosis than patients with normal nutritional status.
There are several reasons for weight loss in patients with CF, including uncontrolled malabsorption, the development of diabetes mellitus, or the progression of respiratory disease. Recurrent episodes of pulmonary sepsis can result in wasting due to an increase in metabolic rate and because the patient may become too breathless to eat properly. Cachexia is also known to be a poor prognostic sign in patients with other medical conditions such as cancer, AIDS, and chronic heart failure. ${ }^{6-8}$ Although there are different mechanisms responsible for the wasting process in these conditions, the common finding appears to be that cachexia is a strong predictor of impaired survival. Furthermore, it is known that improvements in nutrition can lead to increased survival of patients with CF. In a study comparing the survival rates of two large CF centres in North America, there was a higher median survival rate among patients in Toronto than in those in Boston because of better nutrition in the former centre. ${ }^{22}$

The present study shows that CF patients with wasting represent a high risk group which should be considered for transplantation at an earlier stage than patients who are not cachectic. Previous work has shown that preoperative body mass index does not influence survival following transplantation, suggesting that cachectic patients should not be denied transplantation unduly while attempts are being made to increase weight. ${ }^{17}$ Percentage ideal weight represents a simple and cost effective measurement which, in addition to \% predicted $\mathrm{FEV}_{1}$, provides an accurate and independent prediction of prognosis in CF.

The authors are grateful to Ms J Turner for her statistical advice.

RS is supported by the Robert Luff Foundation, APB and the Department of Cardiac Medicine are supported by the British Heart Foundation, AJSC is supported by the Viscount Royston Trust Fund, SDA holds a postgraduate fellowship of the MaxDelbrück-Centrum for Molecular Medicine, Berlin, Germany.

1 Hodson ME. Cystic fibrosis. Postgrad Med $\mathcal{F}$ 1984;60:22533

2 Aitken ML, Fiel SB. Cystic fibrosis. Dis Mon 1993;39:1-52.

3 Madden BP, Hodson ME, Tsang V, et al. Intermediate-term results of heart-lung transplantation for cystic fibrosis. Lancet 1992;339:1583-7.

4 Huang NN, Schidlow DV, Szatrowski TH, et al. Clinical features, survival rate, and prognostic factors in young adults with cystic fibrosis. Am f Med 1987;82:871-9.

5 Kerem E, Reisman J, Corey M, et al. Prediction of mortality in patients with cystic fibrosis. N Engl f Med 1992;326: in patients

6 Anker SD, Ponikowski P, Varney S, et al. Wasting as independent risk factor for mortality in chronic heart failure . Lancet 1997;349:1050-3.

7 Souhami R. Cancer: clinical features and management. In: Wetherall DJ, Ledingham JGG, Warrell DA, eds. Oxford textbook of medicine. 3rd ed. Oxford: Oxford University Press, 1996:240-2.

8 Chlebowski RT, Grosvenor MB, Bernhard NH, et al. Nutritional status, gastrointestinal dysfunction, and survival in patients with AIDS. Am f Gastroenterol 1989;84:1288-93.

9 Quanjer PH, Tammeling GJ, Cotes JE, et al. Lung volumes and forced ventilatory flows. Report Working Party Standardization of Lung Function Tests, European Community for Steel and Coal. Official Statement of the European Respiratory Society. Eur Respir F Suppl 1993;16:5-40.

10 Rosenthal M, Bain SH, Cramer D, et al. Lung function in white children aged 4 to 19 years: I. Spirometry. Thorax 1993;48:794-802.

11 Tanner JM, Whitehouse RH, Takaishi M. Standards from birth to maturity for height, weight, height velocity, and weight velocity: British children, 1965. II. Arch Dis Child 1966;41:613-35. 
12 Metropolitan height and weight tables. Stat Bull Metrop Life Found 1983;64:3-9.

13 Miller ST, Sleeper LA, Pegelow CH, et al. Prediction of adverse outcomes in children with sickle cell disease. $N$ Engl f Med 2000;342:83-9.

14 Dodge JA. Nutritional requirements in cystic fibrosis: a review. F Pediatr Gastroenterol Nutr 1988;7(Suppl 1): S8-11.

15 Sharma R, Rauchhaus M, Ponikowski PP, et al. The relationship of the erythrocyte sedimentation rate to inflammatory cytokines and survival in patients with chronic heart failure treated with angiotensin-converting enzyme inhibitors. F Am Coll Cardiol 2000;36:523-8.

16 Hudson I, Phelan PD. Are sex, age at diagnosis, or mode of presentation prognostic factors for cystic fibrosis? Pediatr Pulmonol 1987;3:288-97.

17 Snell GI, Bennetts K, Bartolo J, et al. Body mass index as a predictor of survival in adults with cystic fibrosis referred for lung transplantation. 7 Heart Lung Transplant 1998;17: 1097-103.

18 Rosenfeld M, Davis R, FitzSimmons S, et al. Gender gap in cystic fibrosis mortality. Am F Epidemiol 1997;145:794-803.

19 Ramsey BW, Farrell PM, Pencharz P. Nutritional assessment and management in cystic fibrosis: a consensus report. The Consensus Committee. Am f Clin Nutr 1992;55:108-16.

20 Weigley ES. Average? Ideal? Desirable? A brief overview of height-weight tables in the United States. F Am Diet Assoc 1984;84:417-23.

21 Waterlow J, Rutishauser I. Malnutrition in man. Early malnutrition and mental development. Sweden: Almquist and Wiksell, 1974.

22 Corey M, McLaughlin FJ, Williams M, et al. A comparison of survival, growth, and pulmonary function in patients with cystic fibrosis in Boston and Toronto. $\mathcal{F}$ Clin Epidemiol 1988;41:583-91.

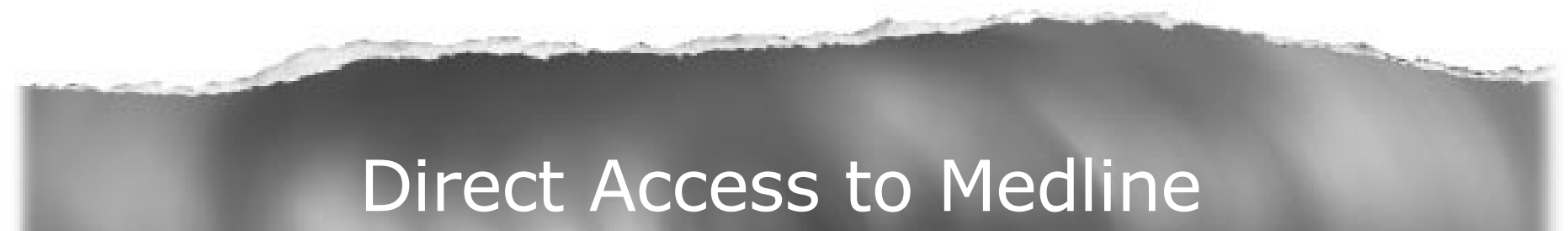

\section{Medline}

Link to Medline from the homepage and get straight into the National Library of Medicine's premier bibliographic database. Medline allows you to search across 9 million records of bibliographic citations and author abstracts from approximately 3,900 current biomedical journals.

\section{www.thoraxjnl.com}

